\title{
TLX1 and NOTCH coregulate transcription in T cell acute lymphoblastic leukemia cells
}

\author{
Irene Riz'1, Teresa S Hawley², Truong V Luu³, Norman H Lee*3 and Robert G Hawley*1
}

\begin{abstract}
Background: The homeobox gene TLX1 (for T-cell leukemia homeobox 1, previously known as HOX 11) is inappropriately expressed in a major subgroup of T cell acute lymphoblastic leukemia (T-ALL) where it is strongly associated with activating NOTCH1 mutations. Despite the recognition that these genetic lesions cooperate in leukemogenesis, there have been no mechanistic studies addressing how $T L X 1$ and NOTCH1 functionally interact to promote the leukemic phenotype.

Results: Global gene expression profiling after downregulation of TLX1 and inhibition of the NOTCH pathway in ALLSIL cells revealed that TLX1 synergistically regulated more than $60 \%$ of the NOTCH-responsive genes. Structurefunction analysis demonstrated that TLX1 binding to Groucho-related TLE corepressors was necessary for maximal transcriptional regulation of the NOTCH-responsive genes tested, implicating TLX1 modulation of the NOTCH-TLE regulatory network. Comparison of the dataset to publicly available biological databases indicated that the TLX1/ NOTCH-coregulated genes are frequently targeted by MYC. Gain- and loss-of-function experiments confirmed that MYC was an essential mediator of TLX1/NOTCH transcriptional output and growth promotion in ALL-SIL cells, with TLX1 contributing to the NOTCH-MYC regulatory axis by posttranscriptional enhancement of MYC protein levels. Functional classification of the TLX1/NOTCH-coregulated targets also showed enrichment for genes associated with other human cancers as well as those involved in developmental processes. In particular, we found that TLX1, NOTCH and MYC coregulate CDIB and RAG1, characteristic markers of early cortical thymocytes, and that concerted downregulation of the TLX1 and NOTCH pathways resulted in their irreversible repression.

Conclusions: We found that TLX1 and NOTCH synergistically regulate transcription in T-ALL, at least in part via the sharing of a TLE corepressor and by augmenting expression of MYC. We conclude that the TLX1/NOTCH/MYC network is a central determinant promoting the growth and survival of TLX1+T-ALL cells. In addition, the TLX1/NOTCH/MYC transcriptional network coregulates genes involved in T cell development, such as CD1 and RAG family members, and therefore may prescribe the early cortical stage of differentiation arrest characteristic of the TLX1 subgroup of T-ALL.
\end{abstract}

\section{Background}

Homeodomain-containing transcription factors play a major role in the establishment of metazoan body plans and organogenesis. They are also involved in the maintenance of tissue homeostasis, influencing the self-renewal and differentiation of stem cells and their progenitors. A number of experimental investigations have demonstrated that homeodomain transcription factors regulate multiple cellular functions including cell growth, prolifer-

* Correspondence: phmnhl@gwumc.edu, rghawley@gwu.edu

1 Department of Anatomy and Regenerative Biology, The George Washington University Medical Center, Washington, DC, USA

3 Department of Pharmacology and Physiology, The George Washington University Medical Center, Washington, DC, USA

Full list of author information is available at the end of the article ation, apoptosis, communication, adhesion and migration $[1,2]$. It is not surprising therefore that anomalous expression of homeobox genes can disrupt developmental programs and contribute to neoplasia [3,4].

TLX1 is an evolutionarily conserved member of the NKL (NK-Like or NK-Linked) subclass of Antennapedia homeobox genes. During normal development, TLX1 is required for the formation of the spleen and participates in certain neuronal cell fate decisions [5-7]. Although $T L X 1$ is not normally expressed in the hematopoietic system, its inappropriate expression due to chromosomal translocations involving $\mathrm{T}$ cell receptor (TCR) genes is associated with about $30 \%$ of adult and approximately $8 \%$ of childhood T-cell acute lymphoblastic leukemia (T- 
ALL) cases $[3,8]$. T cell transforming activity of $T L X 1$ has been confirmed experimentally in studies of murine bone marrow transplant recipients that received hematopoietic stem cells expressing a retrovirally-delivered TLX1 transgene $[9,10]$. However, a long latency of TLX1-induced tumorigenesis indicated the necessity for additional genetic abnormalities. In this regard, mutations activating NOTCH1 are observed in virtually all TLX1+ T-ALL samples [11-13], arguing that the two factors frequently cooperate in the neoplastic conversion of $\mathrm{T}$ cell progenitors. NOTCH stimulates the PI3K-AKT-mTOR pathway and transcriptionally activates the NF- $\mathrm{kB}, \mathrm{MYC}$ and HES1 transcription factors in T-ALL cells, but the critical target genes responsible for the NOTCH1-induced malignant phenotype remain to be fully defined [14-19].

The NOTCH receptor family plays an important role in $\mathrm{T}$ cell development by providing instructional and growth promoting signals $[20,21]$. Intrathymic $\mathrm{T}$ cell differentiation is associated with sequential changes in the expression of the CD1, CD3, CD4 and CD8 cell surface markers [22,23]. Early thymocyte precursors do not express $\mathrm{CD} 3$, $\mathrm{CD} 4$ or $\mathrm{CD} 8$. In-frame TCR $\beta$ rearrangement and the generation of a functional pre-TCR complex (TCR $\beta /$ pre-TCR $\alpha / C D 3)$ at the cell surface allows continued thymocyte development via the process of $\beta$ selection. In humans, CD4 is transiently upregulated following $\beta$-selection and the immature single positive (ISP) $\mathrm{CD} 4^{+}$cells rapidly give rise to $\mathrm{CD} 4{ }^{+} \mathrm{CD} 8^{+}$double positive (DP) cells which undergo further maturation toward two distinct populations represented by $\mathrm{CD} 44^{+}$or $\mathrm{CD} 8^{+}$single positive (SP) phenotypes. NOTCH and/or pre-TCR signaling provide survival and trophic functions until the late DP stage when the cells become highly positive for CD3 and depend on TCR signaling [24,25]. Specifically, $\mathrm{NOTCH}$ signaling was shown to be obligatory for $\beta$ selection [26], and the direct transcriptional target of $\mathrm{NOTCH}, M Y C$, is a central integrator of NOTCH-mediated survival $[27,28]$ and preTCR-mediated proliferative signals $[29,30]$. Surface expression of the CD1 family of genes increases until the late DP stage, after which their expression is extinguished and remains off in $\mathrm{CD}_{4}{ }^{+}$and CD8 ${ }^{+}$SP cells $[31,32]$. TLX1+ T-ALL samples exhibit a predominantly $\mathrm{CD} 1{ }^{+} \mathrm{CD} 3-$ surface phenotype with high levels of TCR recombination activating gene (RAG1) expression and TCR $\beta$ rearrangement on at least one allele; but they often lack cytoplasmic and surface TCR $\beta$ expression, suggesting that the onset of malignant transformation occurs before $\beta$-selection [32-36]. However $\mathrm{TLX} 1+$ leukemic cells are characteristically $\mathrm{CD} 4{ }^{+} \mathrm{CD} 8{ }^{+}$, indicating that the oncogenic network allows the cells to bypass the $\beta$-selection checkpoint and arrest at the early cortical DP stage.
The direct transcriptional targets of NOTCH are tightly regulated such that they are repressed in the absence of a NOTCH activating signal [12,37]. In Drosophila, Groucho, a homolog of Transducin-like Enhancerof-split (TLE) proteins, directly associates with the Suppressor of Hairless (the homolog of human RBP-Jк) repressor complex to block transcription from $\mathrm{NOTCH}-$ responsive elements [38]. In mammals, SPEN/SHARP, a different RBP-JK-associated corepressor protein performs this function [39]. Instead, as was shown for the best characterized target of NOTCH, HES1 (reviewed in [40]), TLE proteins are involved in modulating NOTCH output by a mechanism that involves autorepression of HES1 via formation of a repressive HES1-TLE complex that recognizes an N-box sequence in the HES1 promoter [41]. Moreover, the levels of HES1-repressive activity have been shown to define the type of NOTCH response, e.g., whether it is repressed, oscillating or strongly activated [42]. It is noteworthy that transcriptional repression in response to $\mathrm{NOTCH}$ signaling occurs via an indirect mechanism through downstream effectors; among these, HES1-TLE repressor complexes play a central role, a wellstudied example of which is in the context of $\mathrm{NOTCH}$ antineurogenic activity [43]. Thus, TLE corepressors contribute to two aspects of NOTCH signaling: establishing negative loops of regulation and mediating $\mathrm{NOTCH}$ repressor activity. TLE proteins are also emerging as focal points for crosstalk between signaling pathways [44,45]. Additionally, there is mounting evidence that the expression of TLE genes is altered in a growing list of human cancers [46], including hematologic malignancies [41,47].

We recently showed that TLX1 interacts with TLE1 via an Engrailed homology 1 (Eh1) motif (FXIXXIL, where X can be any amino acid) encompassing amino acids 19-26 $[46,48]$, and proposed that TLX1 activates transcription at least in part by derepressing TLE-controlled genes [49]. Here we demonstrate that TLX1-TLE interaction contributes in a positive manner to $\mathrm{NOTCH}$ transcriptional programs in T-ALL. Functional classification of the overlapping targets of these cooperating genetic lesions showed enrichment for genes associated with other human cancers as well as those involved in developmental processes. We found that TLX1 augments the NOTCH-MYC regulatory axis by enhancing MYC protein levels and that this represents a major component of TLX1-mediated growth control in ALL-SIL cells. We further show that MYC coregulates a significant proportion of common TLX1/NOTCH targets, among them the $C D 1 B$ and $R A G 1$ genes characteristic of the early cortical phenotype exhibited by TLX1+ T-ALLs [32-36]. Downregulation of TLX1 in concert with NOTCH blockade resulted in irreversible repression of these genes. There- 
fore, our data suggest that the TLX1/TLE/NOTCH/MYC network contributes to the pathogenesis of T-ALL by concomitantly promoting the differentiation arrest and expansion of cells at the $\mathrm{CD} 1^{+}$early cortical DP stage of thymocyte development.

\section{Results}

TLX1 signature genes in T-ALL cells

In an effort to identify TLX1 target genes critical to the malignant phenotype in T-ALL, we recently performed gene expression profiling of a patient-derived TLX1+ TALL cell line (ALL-SIL) where TLX1 was downregulated by a lentiviral TLX1 shRNA knockdown approach [50]. Despite selection for vector-encoded drug resistance, there was a certain degree of heterogeneity in TLX1 levels within the transduced cells [50]. We therefore sought to devise a strategy to obtain more homogeneous ALLSIL populations, ideally having more defined levels of TLX1 expression. In that study, we observed that downregulation of TLX1 was associated with decreased levels of $C D 1 B$ and increased levels of $C D 55$ at the mRNA level and on the cell surface [50]. Based on those findings, we used fluorescence-activated cell sorting (FACS) to isolate the following ALL-SIL populations: cells with shRNAmediated knockdown of TLX1 were sorted for a CD1b LowCD55 High surface phenotype (predicted "low" TLX1), and control vector-transduced cells were sorted into $\mathrm{CD} 55^{\text {High }}$ (predicted intermediate or "medium" TLX1) and CD55 Low (predicted "high" TLX1) populations. As anticipated, TLX1 protein levels in the resulting populations exhibited an inverse correlation with surface expression of CD55 ( $r=-0.9)$ (Figure 1A). We performed expression profiling of the sorted TLX $1^{\text {High }}$, TLX $1^{\text {Med }}$ and TLX1Low ALL-SIL cells to identify transcripts whose changes in expression levels correlated with TLX1 protein levels. To globally validate and extend our previous data, which was carried out using an Affymetrix oligonucleotide microarray [50], we chose a 39,936 element cDNA microarray for these experiments [51] (see ref. [52]) (Additional file 1). The datasets of candidate TLX1responsive genes obtained using these two expression platforms overlapped significantly $(P<0.0001)$, yielding a robust consensus set of TLX1 signature genes (Figure 1B, C).

To rule out off-target effects of the TLX1 shRNA, we wanted to assess whether reintroduction of wild-type TLX1 would reverse the knockdown impact on the expression levels of representative genes selected from the TLX1 signature gene list (see Figure 2B). In the experiments described above, we downregulated endogenous TLX1 using an shRNA (TLX1 shRNA95) directed against the TLX1 coding region. To independently corroborate target gene expression changes and to facilitate rescue experiments by ectopic TLX1 expression, we used a different shRNA (TLX1 shRNA93) directed against the 3' noncoding region of TLX1 mRNA. After lentiviral delivery of TLX1 shRNA93 and sorting for a CD1b ${ }^{\text {Low }}$ CD55 $55^{\text {High }}$ surface profile, retroviral vectors expressing the coding region of wild-type TLX1 (TLX1 WT) and two mutant TLX1 proteins were stably introduced into the TLX1 knockdown cells (Figure 1D). As shown in Figure 1E, regulation by TLX1 was confirmed for the selected genes (DTX1, GAS1, HMGA2, L1TD1, PLAC8, SH3BP5, SLC44A1) $(P<0.05$, TLX1 WT vs GFP control). GAS1, HMGA2, L1TD1 and PLAC8 expression required TLX1 DNA-binding activity since introduction of a DNA binding-deficient form of TLX1 carrying a mutation within the homeodomain (TLX1 N51A) [53] had minimal if any activity $(P<0.05$, TLX1 WT vs TLX1 N51A).

In other recent work, we reported that TLX1 binds the TLE1 corepressor in an Eh1-dependent manner [49], and we demonstrated that this interaction is important for transcriptional activation of two known TLX1 target genes, Aldh1a1 and Fhl1 in NIH3T3 cells [54,55]. We therefore wished to determine whether any of the selected TLX1-responsive genes in human T-ALL cells similarly depend on the Eh1 motif. Notably, we found that introduction of a TLE binding-deficient mutant of TLX1 (TLX1 F19E, with a Phe 19 to Glu mutation within the Eh1 motif) [49] significantly diminished the effect obtained by TLX1 reconstitution-of-function for GAS1, PLAC8 and SH3BP5 $(P<0.05$, TLX1 WT vs TLX1 F19E) (Figure 1E). The data thus suggested that DNA-binding activity and/or TLE interaction are important for TLX1mediated transcriptional regulation of the studied TLX1 signature genes.

\section{TLX1 and NOTCH coregulate transcription on a global scale}

Toward the identification of transformation-essential TLX1 targets, we employed an elegant approach recently described by Land and colleagues, who found that the gene sets that were coregulated by loss-of-function p53 and Ras activation, but not the targets of either genetic lesion alone, were enriched in genes required for in vivo tumorigenic potential [56]. Since activating NOTCH1 mutations are tightly associated with TLX1+ T-ALL [1113], we were interested in investigating whether there was a potential cooperation between NOTCH and TLX1 in the control of target gene expression underlying leukemic cell growth, especially in view of the role of TLE proteins in NOTCH signaling [41-43]. T-ALL-associated mutations in NOTCH1 occur in the extracellular heterodimerization (HD) domain and/or the C-terminal PEST domain of the protein: HD domain mutations increase the rate of production of the intracellular form of $\mathrm{NOTCH} 1$ and mutations that eliminate the PEST domain 


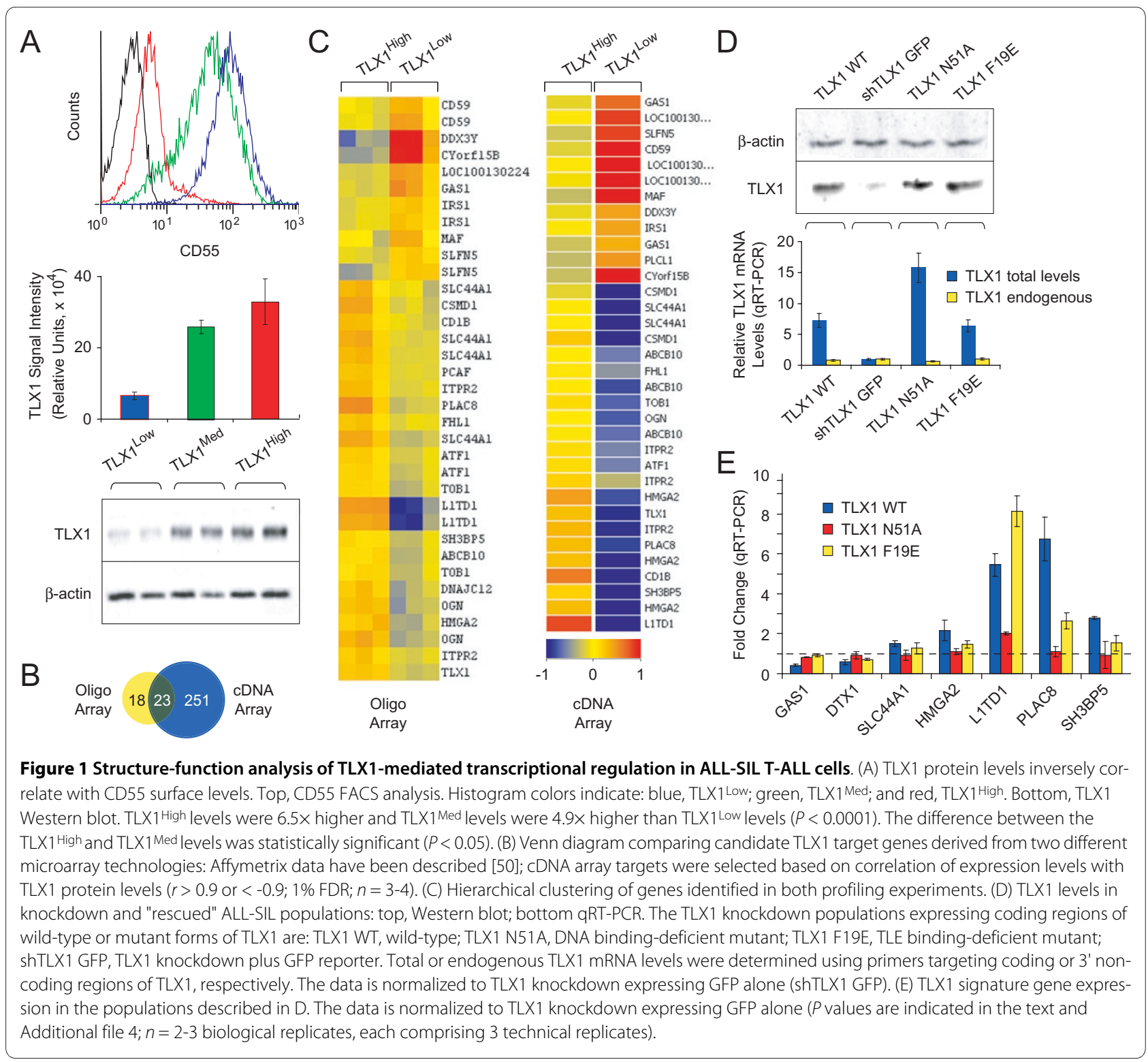

increase protein half-life [57]. ALL-SIL cells harbor gainof-function NOTCH1 mutations in both the HD domain and the PEST domain [11]. This NOTCH1 mutant still requires cleavage by $\gamma$-secretase to generate the mature intracellular form which translocates to the nucleus to regulate gene transcription. Therefore, we used the $\gamma$ secretase inhibitor (GSI) Compound E [11] to downregulate NOTCH pathway signaling in the ALL-SIL cellderived populations described above expressing three different levels of TLX1. GSI treatment was with $500 \mathrm{nM}$ Compound $\mathrm{E}$ and RNA was prepared 24 hours posttreatment as described previously [14]. In total, we generated six different experimental conditions - high, medium or low TLX1 levels treated with GSI or vehicle control (DMSO) - and performed expression profiling experiments using cDNA arrays as described above. Principal
Component Analysis indicated that transcription on a global scale was more profoundly affected by downregulation of TLX1 than by inhibition of NOTCH signaling; i.e., larger sets of genes were found to be responsive to changes in TLX1 levels than to GSI treatment (Additional files 1 and 2). Sets of TLX1-responsive genes derived from GSI- or DMSO- treated cells overlapped significantly as did sets of GSI-responsive genes identified under the conditions of high or low TLX1 levels $(P<$ 0.0001) (Figure 2A). Using the DAVID gene ontology classification tool, we performed comparative analysis of the functions of the genes responsive to $\mathrm{NOTCH}$ in the presence or absence of TLX1 and searched for GO terms uniquely associated with either of these conditions. The best DAVID score for $\mathrm{TLX} 1^{+}$conditions was associated with the GO term "response to external stimulus" $(P<$ 


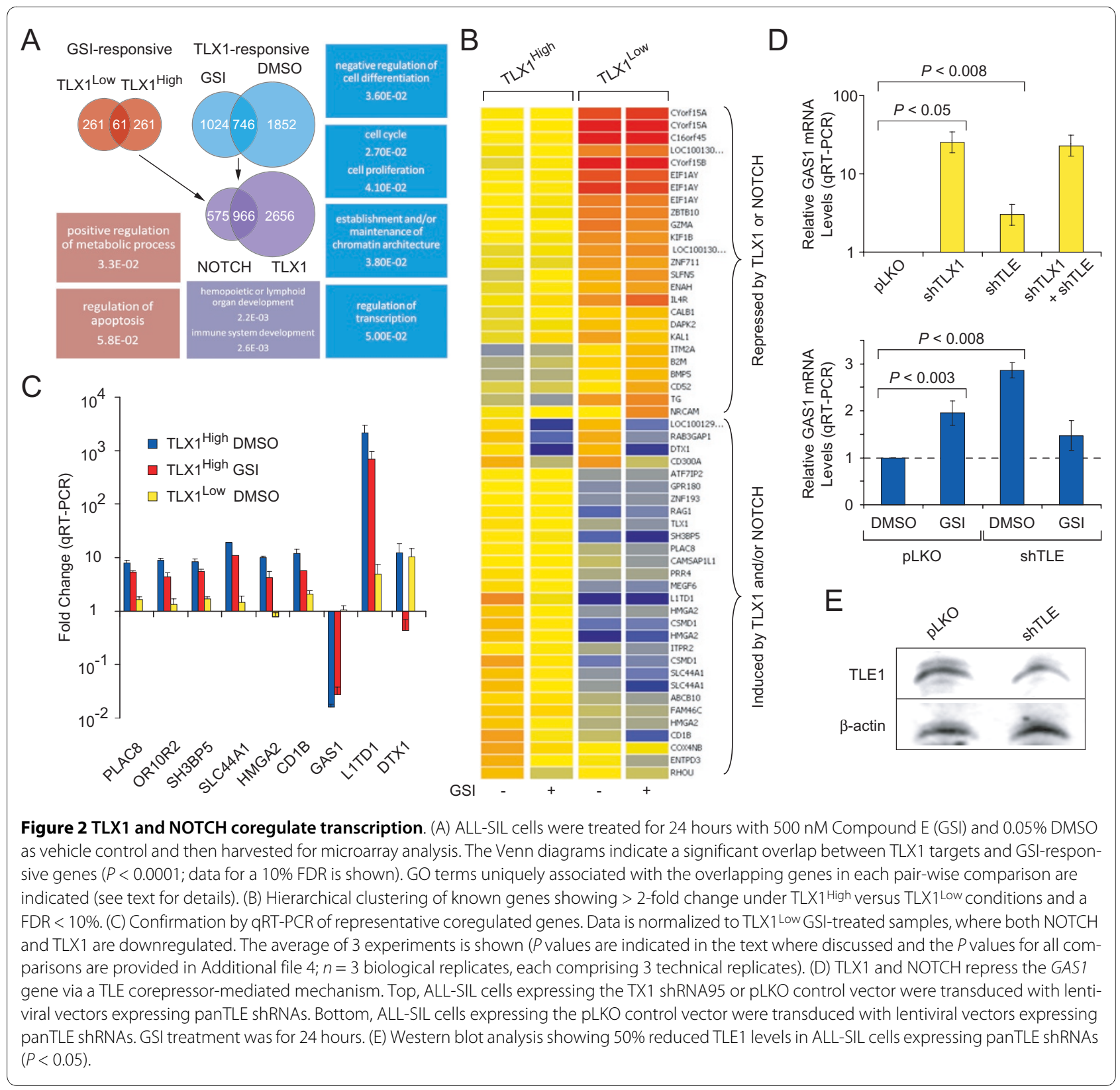

0.001 , representing $8 \%$ of the subset under high TLX1 conditions and $P<0.001$, representing $6.7 \%$ of the subset under medium TLX1 conditions) whereas the best score in the absence of TLX1 expression was associated with the GO term "nervous system development" $(P<0.006$, representing $8.8 \%$ of the subset). This data suggested that expression of TLX1 may influence the functional outcome of NOTCH pathway activation.

Strikingly, the lists of GSI-responsive genes and TLX1responsive genes overlapped very strongly: more than $60 \%$ of the GSI-responsive genes were also controlled by TLX1 (Figure 2A), indicating that a significant fraction of $\mathrm{NOTCH}$ target genes in ALL-SIL cells is coregulated by TLX1 $(P<0.0001)$. To quantitatively compare the indi- vidual contributions of TLX1 and NOTCH in the regulation of common targets, we identified those genes that are differentially expressed in ALL-SIL cells where TLX1 and NOTCH are "on" versus cells where both factors are "off" (i.e., GSI-treated TLX1 ${ }^{\text {Low }}$ cells) (Additional file 3). As summarized in Figure 2B, downregulation of TLX1 and inhibition of NOTCH affected the regulation of the vast majority of genes in the same direction. We found that approximately half of the TLX1-induced genes showed the highest expression levels in the presence of $\mathrm{NOTCH}$ signaling. Interruption of the transcriptional output of either factor led to the downregulation of these genes. Less than $10 \%$ showed a much stronger response to GSI, exhibiting downregulation upon GSI treatment 
and a somewhat more complex response to TLX1 knockdown. One such example, the NOTCH target gene, DTX1 (Deltex1) [58], was chosen for validation by qRT-PCR together with 7 TLX1/NOTCH-coinduced genes (CD1B, HMGA2, L1TD1, OR10R2, PLAC8, SH3BP5, SLC44A1) and one TLX1/NOTCH-corepressed gene (GAS1). The qRT-PCR data reported in Figure $2 \mathrm{C}$ is presented as relative expression levels normalized to levels in GSI-treated TLX1 $1^{\text {Low }}$ cells; thus, a positive value indicates positive regulation by TLX1 and activated NOTCH. Regulation by TLX1 in the presence or absence of NOTCH signaling was demonstrated for all of the putative TLX1/NOTCHcoinduced genes examined $(P<0.05)$, and by NOTCH under conditions of high or low TLX1 expression $(P<$ 0.05 , for at least one TLX1 expression condition; see Additional file 4 for a complete list of $P$ values) (Figure $2 C)$. In support of the generality of these latter results, it had previously been reported that PLAC8, SH3BP5 and $S L C 44 A 1$ were downregulated following $\mathrm{NOTCH}$ inhibition with a different GSI in a different T-ALL-derived cell line [59] (see also Additional file 5). Regulation of the $\mathrm{NOTCH}$ target gene DTX1 by TLX1 was also confirmed in this series of experiments (Figure 2C). As expected, DTX1 showed significantly lower levels of expression following GSI treatment $(P<0.05)$. Interestingly, under conditions of NOTCH inhibition, DTX1 mRNA levels were higher in TLX1 $1^{\text {Low }}$ cells than in TLX1 $1^{\text {High }}$ cells $(P<0.05)$, reaffirming the complexity of the DTX1 response to TLX1/NOTCH coregulation suggested by the microarray data.

We also verified in this series of experiments that GAS1 was repressed by TLX1 $(P<0.001)$ (Figure $2 C)$. Since the Eh1 TLE-binding motif mutant of TLX1 (TLX1 F19E) exhibited markedly reduced GAS1 repressive activity $(P<$ 0.02 ) (Figure $1 \mathrm{E}$ ), we decided to directly investigate the potential contribution of TLE corepressors to the GAS1 repression mechanism. ALL-SIL cells expressing the TLX1 shRNA95 or PLKO control vector were transduced with lentiviral vectors expressing panTLE shRNAs. As seen in Figure 2D, knockdown of TLE resulted in partial derepression of GAS1 in the presence of TLX1 $(P<$ $0.008)$. In contrast, no effect was observed under conditions of low TLX1 expression $(P=0.6)$, indicating that TLX1 is required for repression of GAS1. The magnitude of derepression achieved by TLE knockdown ( 3-fold) was much less than that obtained following TLX1 knockdown ( 40-fold), presumably due in part to incomplete knockdown of TLE. A representative Western blot shown in Figure $2 \mathrm{E}$ indicates that only $\sim 50 \%$ downregulation of TLE1 protein levels was obtained $(P<0.05)$. In this series of experiments, GSI treatment also resulted in partial derepression of GAS1 in the presence of TLX1 ( 2-fold, $P<0.003$ ) (Figure 2D) supporting the data presented in Figure $2 \mathrm{C}$ indicating involvement of NOTCH. Notably, knockdown of TLE resulted in partial derepression of GAS1 in the presence of activated NOTCH $(\sim 3$-fold, $P<$ $0.008)$ but had no significant additional effect when $\mathrm{NOTCH}$ was inhibited. Collectively, the data for GAS1 supported the hypothesis that TLE corepressors can serve as common cofactors in the regulation of certain TLX1/NOTCH-corepressed genes.

To compare the cellular functions regulated by TLX1 and NOTCH together or by either factor separately, we performed a functional classification of gene sets that were enriched for NOTCH only-induced genes, TLX1 only-induced genes and TLX1/NOTCH-coinduced genes. DAVID analysis revealed that all three datasets were enriched for functional GO terms associated with developmental processes. In agreement with the well-recognized survival function of $\mathrm{NOTCH}$ in normal and malignant $\mathrm{T}$ cells, we found that the gene set induced by $\mathrm{NOTCH}$ alone was specifically enriched for GO terms "positive regulation of metabolism" and "apoptosis" $[14,15,27]$, whereas genes only induced by TLX1 were enriched for GO terms associated with "chromatin function and regulation", "proliferation" and "cell-cycle" [60]. Importantly, GO terms associated with "immune system development" and "oncogenesis" only appeared in the set of genes regulated by both TLX1 and NOTCH (Figure 2A). Notably, HMGA2 and PLAC8 were previously reported to be among the 'cooperation response genes' identified by loss-of-function p53 and Ras activation as contributing to the malignant phenotype in colon cancer [56]. A role of HMGA2 in embryonic growth and development has also been described [61-63]. Moreover, the mouse orthologs of 4 of the other 6 TLX1/NOTCH-coinduced signature genes verified by qRT-PCR (L1TD1, PLAC8, SH3BP5, SLC44A1) are downregulated during differentiation of mouse embryonic stem cells whereas the TLX1/NOTCH-corepressed target GAS1 is activated during embryonic stem cell differentiation (GEO profiles GDS2905 and GDS2906). These observations indicate that the TLX1/NOTCH leukemic signature shares a common component with an embryonic stem cell-like transcriptional program [64]. Furthermore, CD1b, the cell surface marker characteristic of the early cortical thymocyte stage of differentiation arrest associated with the vast majority of TLX1+ T-ALL cases, was also among the targets coregulated by TLX1 and NOTCH.

\section{TLX1-mediated augmentation of MYC contributes to T-ALL growth regulation}

To understand how TLX1 might modulate NOTCHdependent transcription, we first examined whether TLX1 influences intracellular levels of NOTCH1. We found that neither TLX1 levels nor sorting for CD1/ CD55 affected the levels of activated NOTCH1, whereas, as expected, GSI treatment markedly decreased intracel- 


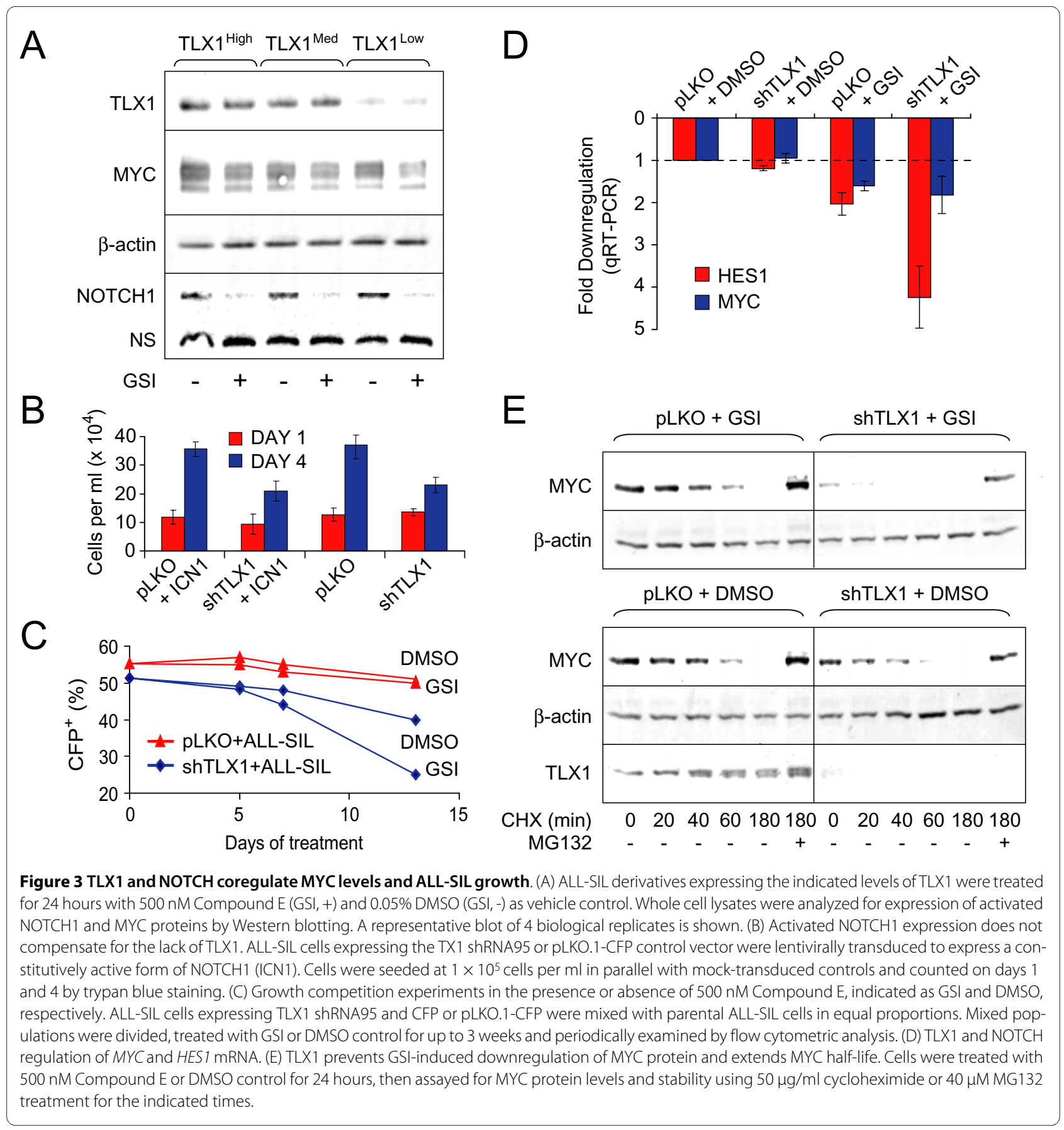

lular levels of NOTCH1 (Figure 3A). We also found that expression of constitutively active form of NOTCH1, ICN1 (encoding the intracellular domain of NOTCH1), does not substitute for the lack of TLX1 in the growth regulation of ALL-SIL cells (Figure 3B). However, as determined by growth competition assay, both factors synergistically regulated ALL-SIL growth, since GSI treatment significantly enhanced the differences between the growth rates of the TLX1-expressing and knockdown populations (Figure 3C). Together, the data suggested that TLX1 and NOTCH utilize different but synergistic mechanisms contributing to the growth of ALL-SIL cells.

We hypothesized that the $M Y C$ gene might represent the master regulatory hub targeted by both oncogenic lesions because TLX1 ${ }^{+}$T-ALLs exhibit increased levels of MYC and MYC target genes [33,60] and NOTCH1 directly activates the $M Y C$ gene at the transcriptional level in T-ALL $[14,15]$. We therefore investigated whether TLX1 and NOTCH coregulate MYC in ALL-SIL cells. MYC protein levels were found to be lowest in TLX1 ${ }^{\text {Low }}$ 
cells treated with GSI (Figure 3A). Notably, TLX1 did not influence $M Y C$ mRNA levels under any conditions; e.g., $M Y C$ mRNA levels decreased following GSI treatment regardless of TLX1 expression $(P<0.05$, GSI- vs DMSOtreated cells) although TLX1 prevented GSI-mediated downregulation of HES1 mRNA $(P<0.05)$ (Figure 3D). We asked next if TLX1 expression contributes to the synthesis or stability of the MYC protein. As shown in Figure 3E, TLX1 increased MYC protein levels in the presence of the MG132 protease inhibitor and, in addition, as seen from cycloheximide treatment, prolonged MYC protein half-life. $\mathrm{NOTCH}$ also positively contributed to total MYC protein levels, consistent with previously published data showing that $\mathrm{NOTCH}$ directly activates $M Y C$ gene expression in T-ALL $[14,15]$. The data thus suggested that TLX1 contributes to the NOTCH-MYC oncogenic axis at least in part via augmentation of MYC protein expression and stability.

Next, we assessed the functional role of TLX1-mediated augmentation of MYC and asked how inhibition of MYC activity affects the growth of ALL-SIL cells. ALLSIL cells were treated with a small-molecule MYC inhibi-

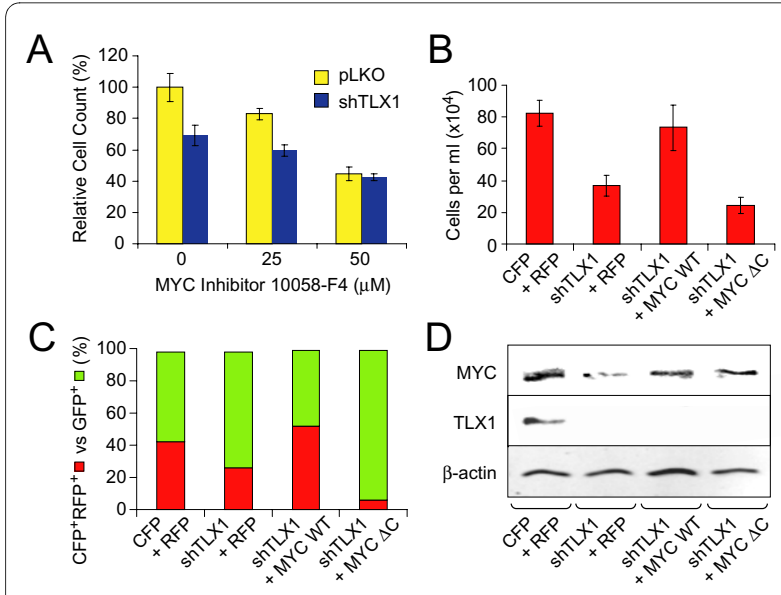

Figure 4 Role of MYC as a downstream component of the TLX1/ NOTCH regulatory network. (A) Chemical inhibition of MYC (10058F4 treatment) mimics TLX1 knockdown in ALL-SIL cells expressing shRNA93 versus pLKO.1-CFP expressing TLX $1+$ controls. (B) Expression of wild-type but not an inactive MYC mutant (MYC $\triangle$ C) compensates for the lack of TLX1 expression in ALL-SIL cells treated with GSI. TLX1 shRNA93 was co-expressed with CFP; MYC constructs were coexpressed with RFP. ALL-SIL cells expressing pLKO.1-CFP-TLX1 shRNA93 were transduced with retroviral vectors coexpressing RFP alone, wildtype MYC plus RFP or the MYC $\triangle$ C mutant plus RFP and sorted for CFP and RFP expression. Equal numbers were seeded and counted after 2 weeks in culture. CFP + RFP, parental ALL-SIL cells coexpressing CFP and RFP. (C) Growth competition experiments. The same CFP+RFP+ ALL-SIL derivatives as in B were mixed with parental ALL-SIL cells expressing GFP in equal proportions. Aliquots were periodically analyzed by flow cytometry; shown are data 2 weeks after initiation of the experiment. (D) Western blot analysis showing MYC protein levels and the corresponding levels of TLX1 for the cell lines studied in B and C. tor, compound 10058-F4 [65,66]. Compound 10058-F4 treatment decreased the growth of ALL-SIL cells to similar levels regardless of TLX1 expression (Figure 4A), suggesting that augmentation of MYC function is a central mechanism of TLX1 contribution to ALL-SIL cell growth. Ectopic expression of wild-type MYC in TLX1 ${ }^{\text {Low }}$ ALL-SIL derivatives fully compensated for the knockdown of endogenous TLX1. On the other hand, an inactive MYC mutant missing an evolutionarily conserved region called MYC homology box II (MYC $\Delta C$ ) [67] was not capable of promoting growth of the cells (Figure 4B, $\mathrm{C})$, as expected [68]. Interestingly, we found that a large fraction of TLX1/NOTCH-targeted genes was represented by potential MYC targets when we compared the expression profiling data with MYC CHIP-on-chip data obtained previously for the $\mathrm{TLX} 3^{+} \mathrm{T}$-ALL-derived cell line HPB-ALL [58] (Additional file 5). Accordingly, we determined that of 8 representative genes coinduced by TLX1 and NOTCH, 6 were inhibited by 10058-F4 treatment (Table 1). Interestingly, PLAC8 expression was upregulated by the MYC inhibitor in agreement with previously published data showing repression of $P L A C 8$ in response to MYC overexpression [69]. Since we found that both TLX1 and NOTCH activated PLAC8, the data suggested that, at least in this case, there is a more complex interplay between the three transcription factors than simple coactivation.

\section{TLX1/NOTCH coregulation of T-cell developmental genes}

The functional classification of the TLX1/NOTCHcoregulated genes suggested that concerted activity of these oncogenes may alter T-cell development. We previously reported that TLX1 downregulation correlates with a decrease in CD1b surface expression in ALL-SIL cells and in another TLX1+ T-ALL cell line (K3P) [50]. Here we investigated whether inhibition of $\mathrm{NOTCH}$ contributes

\section{Table 1: TLX1/NOTCH signature gene response to MYC inhibition in ALL-SIL cells}

\begin{tabular}{lc}
\hline Gene & Fold Downregulation \\
\hline CD1B & $3.6 \pm 0.4$ \\
HMGA2 & $2.4 \pm 0.3$ \\
L1TD1 & $5.9 \pm 0.4$ \\
OR10R2 & $1.9 \pm 0.1$ \\
PLAC8 & $0.5 \pm 0.1$ \\
RAG1 & $11.1 \pm 2.7$ \\
SH3BP5 & $1.2 \pm 0.1$ \\
SLC44A1 & $1.5 \pm 0.1$ \\
\hline
\end{tabular}

Fold downregulation was defined as the ratio of the qRT-PCR values obtained for untreated cells (DMSO) versus cells treated for 2 days with $50 \mu \mathrm{M}$ of the MYC inhibitor 10058-F4. 
to CD1b surface expression as well. First, we characterized the surface phenotype of ALL-SIL cells in greater detail. Although the majority of the cells $(\sim 70 \%)$ are $\mathrm{CD} 4+{ }^{+} \mathrm{CD} 8+{ }^{+} \mathrm{CD} \mathrm{b}^{+/-}$(DP-like), we found that $\sim 30 \%$ exhibit a CD4 ${ }^{+} \mathrm{CD} 8-\mathrm{CD} 1 \mathrm{~b}^{+}$ISP-like phenotype and $\sim 2 \%$ exhibit a CD4-CD8 ${ }^{+} \mathrm{CD}^{-} \mathrm{b}^{-}$SP-like phenotype. When the CD4+CD8-CD1b+ ISP-like population was sorted $(>90 \%$ purity) and returned to continuous culture for 2 weeks, the phenotypic heterogeneity remerged with $\sim 55 \%$ of the cells exhibiting a DP-like CD4+CD $+C D 1 b^{+/-}$phenotype (Figure 5A). Additionally, sorted DP-like populations produced about $2 \%$ SP-like cells (data not shown). Thus, the observed heterogeneity of the surface phenotype of the ALL-SIL line resembles a dynamic system of states reminiscent of a hierarchical organization of malignant T-ALL cells [70], with the majority of cells arrested at the early DP stage typical for TLX1+ T-ALL [32-36]. Downregulation of TLX1 by transduction with an shRNA95-expressing vector followed by puromycin selection or an shRNA93- plus CFP-expressing vector followed by FACS caused a marked decrease in CD1b levels in both ISP-like and DP-like populations. In addition, we found that 2 weeks of GSI treatment decreased CD1b surface expression, predominantly affecting the ISP-like populations; however, when TLX1 was knocked down, GSI treatment caused a decrease in the surface expression of CD1b in both DP- and ISP-like populations. Moreover, the effect of GSI treatment was irreversible in the TLX1 knockdown populations since, even when the cells fully recovered 1 month after GSI treatment, CD1b could not be detected on the cell surface. This is illustrated in Figure $5 \mathrm{~B}$, where it can be seen that the ALL-SIL population balance was shifted toward more mature phenotypes, with reduced percentages of ISP-like, and increased percentages of DP- and SP-like populations.

To determine whether other developmental genes were regulated in a similar manner, we searched for genes that were coregulated with CD1 family members during normal thymocyte development. RAG1 was identified previously as a gene whose expression closely resembles the expression pattern of CD1 [31,32]; specifically, downregulation of both genes occurs at the DP stage, with RAG1 downregulation being required for the DP to SP transition [71,72]. We sorted ISP-like and DP-like populations from ALL-SIL cells with or without TLX1 knockdown and transient $\mathrm{NOTCH}$ inhibition (2 weeks of GSI treatment or DMSO and 1 month recovery). We examined $C D 1 B$ and $R A G 1 \mathrm{mRNA}$ levels in these populations and observed a striking concordance in their expression changes; e.g., temporary inhibition of $\mathrm{NOTCH}$ signaling in TLX1 knockdown populations led to irreversible repression of $C D 1 B$ and $R A G 1$ (Figure $5 C$ ). In addition, ectopic reexpression of TLX1 in CD1b- cells failed to reactivate these genes (data not shown). Thus, we found that transient downregulation of $\mathrm{NOTCH}$ in concert with TLX1 knockdown is required and sufficient to induce irreversible repression of $C D 1 B$ and $R A G 1$. Since the silencing of these genes is an important aspect of the normal T-cell differentiation program, the data suggest that TLX1/NOTCH-coregulated maintenance of their expression exemplifies a mechanism underlying the ALL-SIL differentiation arrest. Interestingly, downregulation of TLE caused a significant decrease in the percentage of $\mathrm{CD}_{1} \mathrm{~b}^{+}$cells, suggesting that TLX1-TLE interaction is involved in the TLX1-imposed differentiation arrest (Figure 5D)

\section{Discussion}

Several lines of evidence indicate that TLX1 functions as a transcriptional regulator that can either activate or repress gene expression $[49,50,53-55,60,73-76]$. The situation is complicated by the fact that TLX1 may switch its mode of regulation of the same gene depending on as yet ill-defined tissue-specific factors that may include the availability of transcriptional cofactors, the presence or state of activation of cis-regulatory DNA elements, and/ or the expression levels of the TLX1 protein itself (our unpublished observations and [54]). Recently, for two of the best characterized DNA binding-dependent TLX1 targets, Aldh1a1 and Fhl1, we reported that TLX1 activates transcription via interaction with the transcriptional corepressor TLE [49]. However, the significance of this observation for TLX1-associated leukemogenesis as well as the leukemia-specific downstream targets of TLX1 still remained elusive. In the present work, using a human cell line derived from a TLX1+ T-ALL patient sample we have identified several genes that were upregulated by TLX1 in a DNA binding-dependent manner. Although statistical significance was only reached for a subset of genes examined, an intact Eh1 TLE-binding motif was necessary for maximal effect in all cases with the exception of L1TD1. Additionally, we identified a potential direct TLX1 target gene, GAS1, which was repressed by TLX1 in a classical TLE and DNA bindingdependent manner [48]. Interestingly, we found that our attempts to overexpress TLE1 by retroviral-mediated gene delivery resulted in massive cell death in TLX1 knockdown derivatives but not in parental ALL-SIL cells (our unpublished observations). Taken together, our data suggest that TLX1 interaction with TLE may be an integral component of TLX1 leukemic function (Figure 6). To explain how TLX1-TLE binding may cause transcriptional activation, we can envisage at least two mechanisms: 1) TLX1-TLE-mediated repression of unknown intermediary transcriptional repressors (referred to as the repressor-of-repressor mechanism [77]); and/or 2) A 


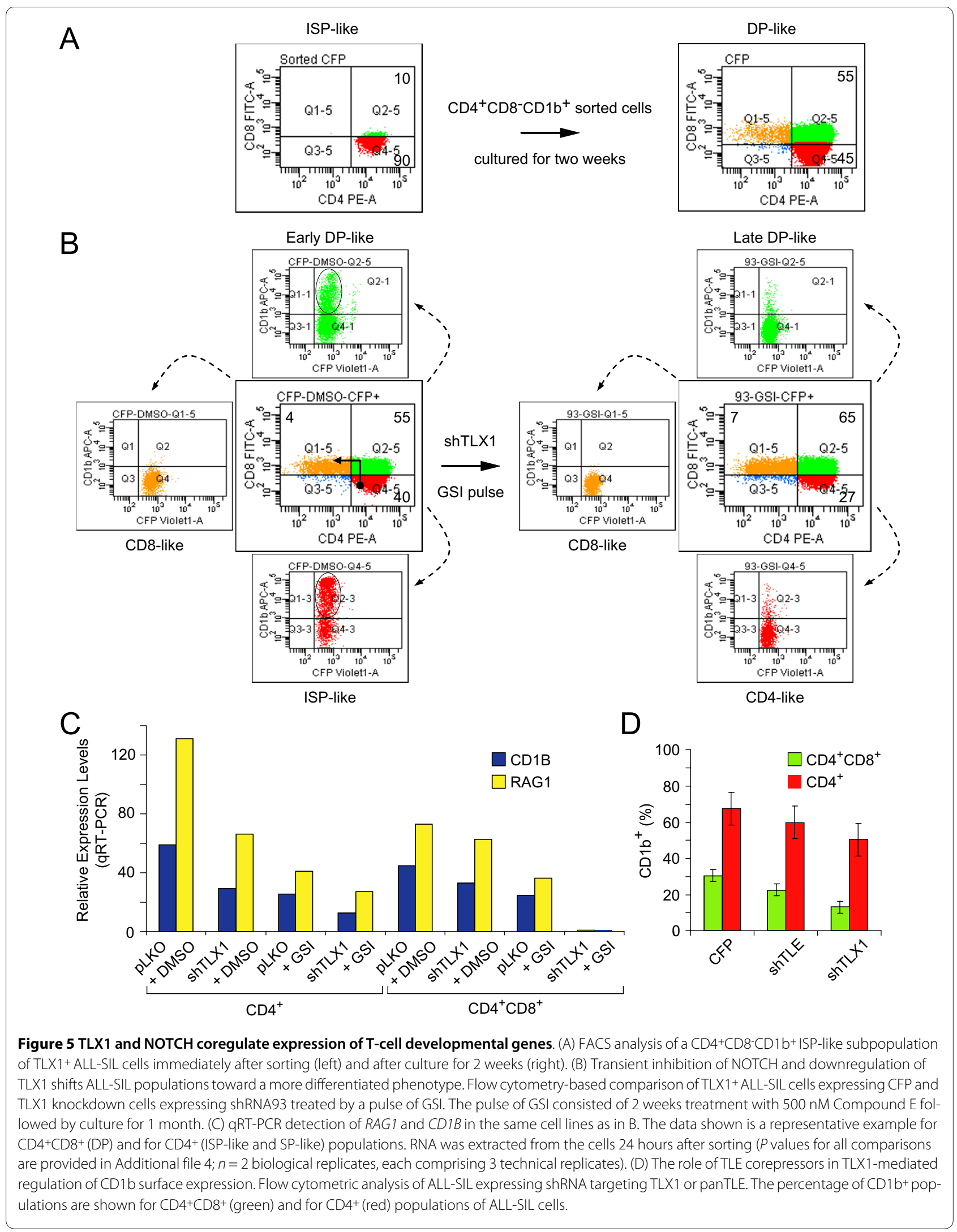




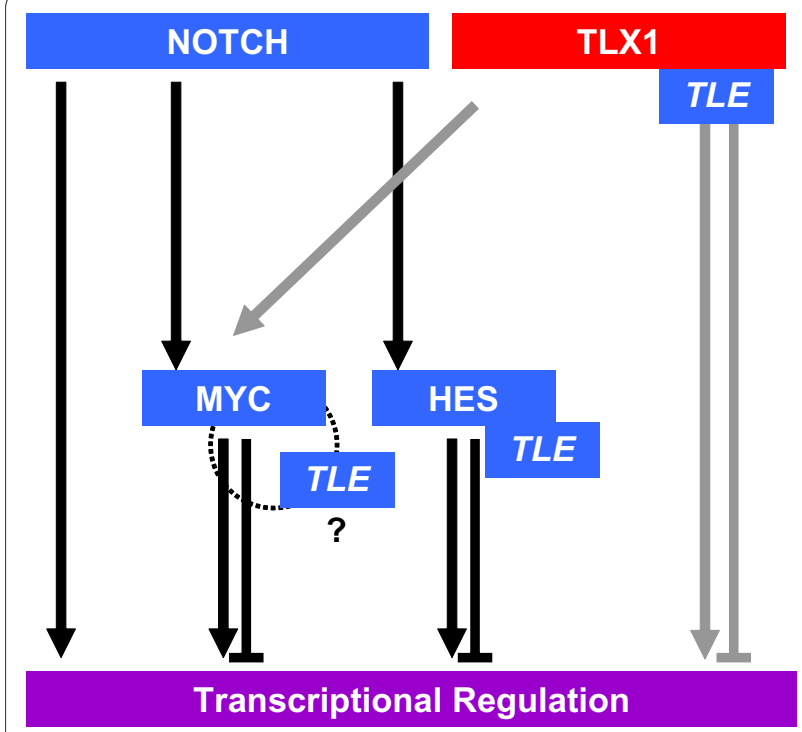

Figure $\mathbf{6}$ Schematic summary of regulatory network controlling TLX1/NOTCH signature genes. NOTCH1 activates transcription of downstream transcriptional regulators MYC and HES. TLX1 augments MYC protein levels. HES represses transcription via interaction with TLE [41-43]. TLX 1 interacts with TLE to mediate repression and activation of transcription [49]. MYC binds TLE directly in vitro [45]. However, it is not known whether TLE is required for MYC repressor activity (indicated by "?"). We speculate that the genes coregulated by the TLX1/TLE/ NOTCH/MYC network are critical for TLX1/NOTCH transforming function in T-ALL.

derepression strategy involving competitive sequestration of TLE from other TLE-dependent transcriptional repressors. To illustrate the validity of the second mechanism, we previously used a well-established HES1-TLEdependent repressor model involving the ASCL1/HASH1 gene and showed that ectopic expression of TLX1 dismissed TLE from the ASCL1 promoter, preventing HES1mediated $A S C L 1$ repression [49].

The TLE protein family plays a role in a negative loop of regulation of $\mathrm{NOTCH}$ as well as facilitating $\mathrm{NOTCH}$ repressor function [38,41]. We found that TLX1 coregulated a large proportion of NOTCH-responsive genes. As was confirmed by qRT-PCR, all of the TLX1 targets requiring the Eh1 TLE-binding motif for their full activation were also positively regulated by $\mathrm{NOTCH}$, implicating TLX1-TLE interaction in the derepression of NOTCH-induced genes. Downregulation of TLE levels by pan-TLE targeting shRNA was associated with partial transcriptional derepression of the GAS1 gene, supporting the idea that TLE is directly involved in NOTCH- and TLX1-mediated corepression of certain genes. The genes induced by TLX1 in a TLE binding-dependent manner also responded to reduced TLE levels but the effects were variable, consistent with multiple indirect modes of TLE involvement. Also, one of the strongest transcriptional activation responses to TLX1 and NOTCH, exhibited by the L1TD1 gene, does not require the Eh1 TLE-binding motif for maximal effect. However, expression of L1TD1 and most of the other TLX1-NOTCH signature genes studied were strongly inhibited by the 10058-F4 MYC inhibitor $[65,66]$. Since we found that TLX1 expression enhances MYC protein levels in ALL-SIL cells and that this is a central facet of TLX1-mediated growth control, we conclude that augmentation of MYC activity is an additional and important aspect of TLX1/NOTCH cooperation. It was previously appreciated that high levels of expression of MYC target genes is a characteristic feature of TLX1+ T-ALLs $[33,60]$. Thus, our results provide an explanation for these observations and link TLX1 to the NOTCH-MYC signaling axis (Figure 6) [14,58]. In retrospect, since the majority of NOTCH-induced genes in TALL are also targeted by MYC [58], it is perhaps not surprising to find that virtually all of the TLX1/NOTCH signature genes that we validated by qRT-PCR negatively responded to inhibition of MYC by compound 10058-F4 treatment. Another level of complexity has arisen with a recent publication showing that mammalian MYC and TLE proteins directly bind in vitro [44]. In that study, the investigators also reported that TLE antagonized MYC transcriptional activation of growth-promoting genes in Drosophila [44]. It is possible therefore that TLX1-mediated modulation of TLE interactions may derepress MYC target genes as well as NOTCH-responsive genes in TALL cells (Figure 6). Finally, promoter analysis of the genes whose expression positively correlated with TLX1 expression showed enrichment for $\mathrm{NOTCH}$-responsive elements (our unpublished observations). Others have shown that TLX1 interacts with SHARP, a corepressor protein directly controlling NOTCH target genes via this element $[78,79]$. Thus, we speculate that TLX1-SHARP interaction may be an additional point of intersection with the NOTCH signaling pathway.

Since GSI targets all NOTCH receptor family members, we deliberately avoided specifying throughout which NOTCH receptor cooperates with TLX1 in ALLSIL cells. However, the fact that NOTCH1 is mutated in these cells [11], considered together with our Western blot results showing that GSI treatment markedly decreased intracellular levels of NOTCH1, strongly implicates activated NOTCH1 in the observed cooperation with TLX1 [11]. It is important to point out, however, that others have suggested that TLX1 may enhance NOTCH3 signaling in T-ALL cells, although no information regarding protein levels or functional activation of the NOTCH3 receptor was provided [78].

TLX1-activating mutations in T-ALL are associated with an early cortical phenotype, suggesting a direct inhibitory effect preventing the differentiation of thymocytes past this developmental stage [32-36]. In experimental models, we and others have observed that TLX1 
expression may lead to differentiation arrest of a broad spectrum of hematopoietic precursors, and that extinction of TLX1 expression released the block allowing continuation of the differentiation program in erythroid precursors conditionally expressing TLX1 $[76,80]$. Moreover, we recently showed that TLX1 downregulation in ALL-SIL cells correlates with acquisition of a surface phenotype associated with early cortical to late cortical thymocyte development epitomized by downregulation of CD1 family members, partially recapitulating the T-cell differentiation program [50]. Here, we have extended the latter studies to demonstrate that the $C D 1 B$ marker of early cortical thymocytes is coregulated by TLX1 and NOTCH concomitant with maintenance of RAG1 expression. Downregulation of RAG1 in cortical thymocytes is one of the earliest signs of positive selection during normal thymocyte development [71,72]. In this context, we found that downregulation of TLX1 and $\mathrm{NOTCH}$ in ALL-SIL cells leads to irreversible repression of the $C D 1 B$ and RAG1 genes, since reexpression of TLX1 in the sorted CD1b-cells or resumption of NOTCH signaling was not sufficient to reactivate their expression. Therefore, the data is consistent with a role of TLX1/NOTCH cooperation in preventing the differentiation-programmed repression of the $C D 1 B$ and $R A G 1$ genes rather than one involving transcriptional activation of $C D 1$ and RAG family members. In addition, we found that $C D 1 B$ and RAG1 were negatively regulated by MYC inhibition. Collectively, these findings implicate the TLX1/NOTCHMYC network in maintaining the $\mathrm{CD}^{+}$early cortical stage of TLX1+ T-ALL cells.

A major motivation for these studies was to identify potential therapeutic targets that are critical to the malignant phenotype in T-ALL. The study design was modeled after that of Land and colleagues who demonstrated in experimental models of murine and human colon cancer that malignancy was strongly correlated with a class of genes they referred to as 'cooperation response genes' which were synergistically regulated by cooperating oncogenic mutations [56]. Based on their observations that the malignant state depended on a similar set of genes in both experimental systems, the investigators suggested that cooperation response genes may broadly contribute to the generation and maintenance of the cancer cell phenotype in a variety of contexts. It is notable therefore that HMGA2 and PLAC8 were among the genes that we identified. HMGA2 belongs to the high mobility group AT-hook family of architectural nuclear factors involved in chromatin remodeling and gene transcription. It is predominantly expressed during normal embryonic development, but has been implicated as contributing to the transformed phenotype and poor prognosis of a wide variety of human neoplasms $[81,82]$ including hematologic malignancies [83-85]. The PLAC8 gene encodes a cysteine-rich protein of unknown function which has been suggested to be involved in cell survival and transformation [69]. It was the top-ranked cooperation response gene identified by Land and colleagues whose perturbation in both murine and human colon cancer cells inhibited tumor formation in mice [56]. Increased expression of PLAC8 has been reported in putative cancer stem cells in liver and breast cancer cell lines [86,87]. More intriguing, the PLAC8 gene was among the gene signatures predictive of relapse in ALL patients in two recent studies $[88,89]$. In particular, in a study of 50 T-ALL patients, PLAC8 was one of 5 genes that accurately predicted clinical outcome [89]. The accumulated data thus support the idea that HMGA2 and PLAC8 may play a central role in the malignant phenotype of a broad spectrum of cancers of diverse origins.

\section{Conclusions}

Despite the fact that the oncogenic function of TLX1 and NOTCH1 is well established in T-ALL, the mechanistic basis of their cooperation remained to be clarified. Our data suggest that in the process of leukemic transformation TLX1 enhances NOTCH signaling output and that both factors contribute to T-ALL cell survival and differentiation arrest. We believe that a search for the common gates targeted by these cooperating genetic lesions will help to better understand the nature of the disease and lead to the development of more effective and less toxic therapeutic regimens. The TLX1/NOTCH 'cooperation response genes' listed in Table 1, especially HMGA2 and $P L A C 8$, represent attractive candidates for further studies along these lines.

\section{Methods}

\section{shRNA knockdown and gene transfer experiments}

ALL-SIL cells were cultured as previously described [60]. TLX1 shRNA knockdown analyses were performed as previously reported [50] with the following modifications. TLX1 shRNAs were obtained from the MISSION ${ }^{\mathrm{m}}$ TRC TLX1 shRNA target set (Cat. No. NM_005521, Sigma-Aldrich) cloned into the pLKO.1-puro lentiviral vector backbone [90]: TRCN0000014993 (designated TLX1 shRNA93) targets sequences within the TLX1 3' noncoding region and TRCN0000014995 (designated TLX1 shRNA95) targets the TLX1 coding region. The pLKO.1-CFP-TLX1 shRNA93, pLKO.1-CFP-TLX1 shRNA95 and pLKO.1-CFP lentiviral vectors were created by replacing the puromycin resistance genes in the corresponding pLKO.1-puro plasmids with the enhanced cyan fluorescent protein (CFP) gene from the MCIN retroviral vector [91,92]. The resulting pLKO.1-CFP lentiviral vector backbone was also used to generate panTLE knockdown ALL-SIL cells. The TLE shRNAs were based on an shRNA (TLE1/4si2) previously shown to efficiently 
knock down TLE1 and TLE4 in human leukemia cells [47]. The TLE shRNA target sequences were as follows: shRNA1/4, GGTCTGCTTCTCATGCTGCAG, which targets sequences in common to both TLE1 and TLE4; shRNA2, GGTTTGCTTCTCCTGCTGCAG, and shRNA3, AGTCTGCTTCTCCTGCTGCAG, which target the corresponding regions in TLE2 and TLE3. Double-stranded DNAs including the 21-mer TLE shRNA sequences [90] were ligated into the AgeI-EcoRI sites of pLKO.1-CFP. The TLX1 wild-type, and the TLX1 N51A and TLX1 F19E mutant coding regions were previously described $[49,53]$; these were inserted into the MSCV$\mathrm{GW}$ retroviral vector that coexpresses the enhanced green fluorescent protein (GFP) gene [93]. MYC retroviral expression vectors were constructed by cloning the MYC wild-type and MYC $\Delta C$ (amino acids 127-189 deleted) mutant coding regions [67] (provided by Dr. William Tansey, Cold Spring Harbor Laboratory, Cold Spring Harbor, NY) into the MSCV-RW retroviral vector in which the GFP gene in MSCV-GW was replaced with the DsRed-Express2 red fluorescent protein (RFP) gene [94] (provided by Dr. Benjamin Glick, The University of Chicago, Chicago, IL). A lentiviral vector that coexpresses a constitutively active form of NOTCH1 encoding the intracellular domain of the human NOTCH1 receptor (ICN1; codons 1770-2555) (provided by Dr. Warren Pear, University of Pennsylvania School of Medicine, Philadelphia, PA) [95] and RFP was previously described [49].

Vesicular stomatitis virus (VSV)-G glycoproteinpseudotyped lentiviral vector particles were produced by transiently transfecting the lentiviral vector plasmids (15 $\mu \mathrm{g})$, the packaging plasmid pCMV $\Delta \mathrm{R} 8.91(10 \mu \mathrm{g})$ and the VSV-G protein envelope plasmid pMD.G $(5 \mu \mathrm{g})$ into subconfluent human embryonic kidney $293 \mathrm{~T}$ cells by the calcium phosphate precipitation method [96], and were used to transduce ALL-SIL cells as previously described [50]. Amphotropic retroviral particles were similarly produced by transiently transfecting 293T cells with retroviral vector plasmids $(10 \mu \mathrm{g})$ and the pCL-Ampho packaging construct $(10 \mu \mathrm{g})$, and were used to transduce ALL-SIL cells as previously described [60].

\section{Fluorescence activated cell sorting and analysis}

Vector-transduced ALL-SIL cells expressing CFP, GFP and/or RFP were sorted on a FACSAria instrument (BD Biosciences) equipped with 407-nm solid state, 488-nm solid state and 633-nm HeNe lasers [91,92]. Where indicated, the cells were stained with anti-CD1b-Alexa Fluor 647 and anti-CD55-PE monoclonal antibodies prior to sorting. Other monoclonal antibodies included, antiCD4-FITC, anti-CD4-PE, anti-CD8-FITC and anti-CD8PE (all purchased from eBioscience). Cell staining was carried out with saturating concentrations of reagents as described [97] and flow cytometry data was analyzed using FACSDiva software (BD Biosciences).

\section{Cell growth assays}

ALL-SIL cell populations expressing fluorescent protein reporters (CFP, GFP or RFP) were mixed in equal proportions and periodically analyzed by flow cytometric monitoring. In some experiments, cell growth was measured using the alamarBlue cell viability and proliferation reagent (Invitrogen) as previously described [50]. Where indicated, ALL-SIL cell populations were treated with the GSI, Compound E, at $500 \mathrm{nM}$ for 24 hours [14] or 2 weeks [11], or with the MYC chemical inhibitor 10058-F4 (both from Calbiochem, EMD Chemicals) at the indicated concentrations as previously described $[65,66]$. MG132 and cycloheximide were from Sigma-Aldrich. Mock-treated cultures contained 0.05\% dimethylsulfoxide (DMSO) as solvent vehicle control.

\section{Quantitative real-time RT-PCR validation and analysis of genes}

Real-time qRT-PCR was performed using the Power SYBR Green reagent (Applied Biosystems) on an ABI Prism 7000 Sequence Detection System as previously described $[76,98]$. Primers: TLX1 coding (CATCGACCAGATCCTCAACA, CAGCCAAGGCCGTATTCTC); TLX1 3' noncoding (GTCACTGTCCCTCCTGGTGT, GCCTGATCGTAAGGTCCAAA); L1TD1 (ACGCCAGGGTGACTACAAAC, GCTGTCCATCCTTCTGGG TA); OR10R2 (CTTTCTGTGGCCAGGACAAT, AACCCATCACACCCAATAGC); HMGA2 (ACTTCAGCCCAGGGACAAC, CTTCCCCTGGGTCTCTTAGG); DTX1 (GCTAATTGTCTTCGGCCAAC, GCTGGCA TCCCTTTAAATCTT); CD1B (GCTCCTTTTGCTATGCCTTG, TATTGCGAATGGGAGAGGAG); RAG1 (T GTTTAATGGCTTCCAAGAGC, ACACAGGTCCCCT GAATCAA); SH3BP5 (GATGCGGTGTTGGTGCTG, AGAAATGGCATCAGGCTCAG); SLC44A1 (TCAAA TGCTTGCTATACAATCTGA, CGTAGAACTCTGGATACTCAATGAA); PLAC8 (GGAGAGCCATGCGTACTTTC, CAAGCTGAAGAGGTGTCTGCT); GAS1 (CGGAGCTTGACTTCTTGGAC, CGTCCTGAACA CTGCAGCTA). qRT-PCR controls, MAPK1, PGK1 and POLR2A, were selected based on the cDNA hybridization data and confirmed not to show any changes in expression under the experimental conditions studied. Primers: MAPK1 (CCAGATCCTCAGAGGGTTAAAA, ATCACAGGTGGTGTTGAGCA); POLR2A (AAGATCCTTCCTTGCCTGTG, GCTTTGTTCTTCCCGAGGAT) and PGK1 (CAGTTTGGAGCTCCTGGAAG, AG TTGACTTAGGGGCTGTGC). The data were normalized per MAPK1 expression levels.

\section{Western blotting}

Western blotting was performed essentially as previously described [53,60,76,97]. Antibodies were: TLX1(c-18, sc880), MYC (c-33, sc-42 and N-262, sc-764), TLE1(M101, sc-9121) and TLE (C-19, sc-13373) from 
Santa Cruz; and anti-Cleaved NOTCH1 (Val1744) from Cell Signaling.

\section{Microarray gene expression analysis}

RNA samples were analyzed with a cDNA microarray (TIGR $40 \mathrm{~K}$ microarray) as previously described [51]. In brief, total RNA was prepared using Trizol reagent (Invitrogen) and the RNeasy mini kit (QIAGEN) as per the manufacturers' instructions. Expression analysis of ALLSIL cells for a particular TLX1 level was derived from three to four independent GSI and DMSO control treatments. For statistical analysis, a biological replicate hybridization experiment was defined as an independent treatment. A hybridization experiment consisted of Cy5labeled cDNA that was reverse transcribed from $15 \mu \mathrm{g}$ of total RNA and cohybridized with Cy3-labeled cDNA synthesized from an equal amount of the Stratagene Universal Human Reference RNA, as described [99,100]. Hybridizations were performed for $18-24$ hours at $42^{\circ} \mathrm{C}$ followed by washing in decreasing concentrations of SSC at room temperature and spun dry. Microarray platform, image scanning, fluorescence intensity measurements, normalization across replicate experiments, experimental noise determination, cluster analysis and candidate signature gene identification were performed as previously described [101-104].

\section{Statistical analysis}

Unless noted otherwise, the Student's unpaired $t$ test was used to compare differences between indicated groups. A $P$ value $<0.05$ was considered significant.

\section{Additional material}

\begin{abstract}
Additional file 1 TLX1 target genes derived from cDNA platform hybridization experiments of ALL-SIL cells with or without GSI treatment. TLX1 targets were selected based on correlations of expression levels with $T L X 1$ protein levels ( $r>0.7$ or $<-0.7 ; 1 \%, 5 \%$ or $10 \%$ false discovery rate [FDR]; $n=3-4)$. The data is organized in 4 spreadsheets: "PositiveCorrel DMSO control", genes whose expression levels positively correlated with TLX1 protein levels in untreated ALL-SIL cells; "NegativeCorrel DMSO control", genes whose expression levels negatively correlated with TLX1 protein levels in untreated ALL-SIL cells; "PositiveCorrel GSI treated", genes whose expression levels positively correlated with TLX1 protein levels in GSItreated ALL-SIL cells; "NegativeCorrel GSI treated", genes whose expression levels negatively correlated with TLX1 protein levels in GSI-treated ALL-SIL
\end{abstract} cells.

Additional file $\mathbf{2}$ GSI-responsive genes. The data is organized in 3 spreadsheets: each spreadsheet represents GSI-responsive genes identified under low ("TLDvsTLG"), medium ("TMDvsTMG") or high ("THDvsTHG") levels of TLX1 expression ( $1 \%, 5 \%$ or $10 \%$ FDR; $n=3-4$ ).

Additional file 3 Genes differentially expressed under conditions where TLX1 is expressed and NOTCH is activated versus conditions where TLX1 and NOTCH are both inhibited. The data is organized in 2 spreadsheets: "THDvsTLG", relative expression levels of genes under conditions of high TLX1 levels and treatment with DMSO versus low TLX1 levels and treatment with GSI; "TMDvsTLG", relative expression levels of genes under conditions of medium TLX1 levels and treatment with DMSO versus low TLX1 levels and treatment with GSI.

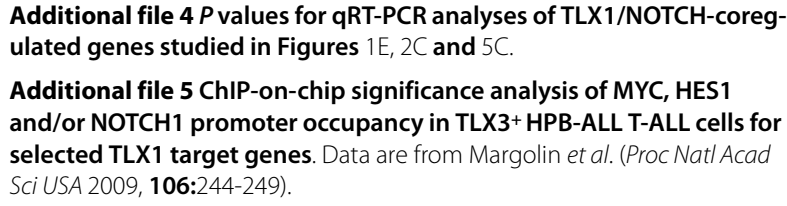

\section{Competing interests}

The authors declare that they have no competing interests.

\section{Authors' contributions}

IR designed the overall study, performed most of the experiments, analyzed and interpreted data, and wrote the manuscript. TSH performed the FACS and flow cytometric analyses, and edited the manuscript. TVL performed the CDNA microarray experiments. NHL contributed to the design of the CDNA microarray experiments, performed statistical analyses of the microarray data, and edited the manuscript. RGH supervised and contributed to the conception and design of the overall study, analyzed and interpreted data, and edited the manuscript. All the authors read and approved the final version of the paper.

\section{Acknowledgements}

We gratefully acknowledge Ali Ramezani for consultation and help with the TLE shRNA lentiviral vector constructions, and we thank Sara Karandish for technical assistance. This work was supported in part by National Institutes of Health grants R01HL66305 (RGH), R01HL65519 (RGH) and R01CA120316 (NHL), and by an Elaine H. Snyder Cancer Research Award and the King Fahd Endowment Fund from The George Washington University Medical Center (RGH).

\section{Author Details}

1Department of Anatomy and Regenerative Biology, The George Washington University Medical Center, Washington, DC, USA, ${ }^{2}$ Flow Cytometry Core Facility, The George Washington University Medical Center, Washington, DC, USA and 3Department of Pharmacology and Physiology, The George Washington University Medical Center, Washington, DC, USA

Received: 12 April 2010 Accepted: 9 July 2010

Published: 9 July 2010

\section{References}

1. Hueber SD, Bezdan D, Henz SR, Blank M, Wu H, Lohmann I: Comparative analysis of Hox downstream genes in Drosophila. Development 2007, 134:381-392.

2. Hombria JC, Lovegrove B: Beyond homeosis--HOX function in morphogenesis and organogenesis. Differentiation 2003, 71:461-476.

3. Owens BM, Hawley RG: HOX and non-HOX homeobox genes in leukemic hematopoiesis. Stem Cells 2002, 20:364-379.

4. Shah N, Sukumar S: The Hox genes and their roles in oncogenesis. Nat Rev Cancer 2010, 10:361-371.

5. Holland PW, Booth HA, Bruford EA: Classification and nomenclature of all human homeobox genes. BMC Biol 2007, 5:47.

6. Roberts CW, Shutter JR, Korsmeyer SJ: Hox 11 controls the genesis of the spleen. Nature 1994, 368:747-749.

7. Cheng L, Arata A, Mizuguchi R, Qian Y, Karunaratne A, Gray PA, Arata S, Shirasawa S, Bouchard M, Luo P, Chen CL, Busslinger M, Goulding M, Onimaru H, Ma Q: T/x3 and T/x1 are post-mitotic selector genes determining glutamatergic over GABAergic cell fates. Nat Neurosci 2004, 7:510-517.

8. Aifantis I, Raetz E, Buonamici S: Molecular pathogenesis of T-cell leukaemia and lymphoma. Nat Rev Immunol 2008, 8:380-390.

9. Hawley RG, Fong AZC, Lu M, Hawley TS: The HOX11 homeoboxcontaining gene of human leukemia immortalizes murine hematopoietic precursors. Oncogene 1994, 9:1-12.

10. Hawley RG, Fong AZC, Reis MD, Zhang N, Lu M, Hawley TS: Transforming function of the HOX11/TCL3 homeobox gene. Cancer Res 1997, 57:337-345

11. Weng AP, Ferrando AA, Lee W, Morris JP, Silverman LB, Sanchez-Irizarry C, Blacklow SC, Look AT, Aster JC: Activating mutations of NOTCH1 in human T cell acute lymphoblastic leukemia. Science 2004, 306:269-271.

12. Aster JC, Pear WS, Blacklow SC: Notch signaling in leukemia. Annu Rev Pathol 2008, 3:587-613. 
13. Asnafi V, Buzyn A, Le NS, Baleydier F, Simon A, Beldjord K, Reman O, Witz F, Fagot $T$, Tavernier $E$, Turlure $P$, Leguay $T$, Huguet $F$, Vernant JP, Daniel $F$, Bene MC, Ifrah N, Thomas X, Dombret H, Macintyre E: NOTCH1FBXW7 mutation identifies a large subgroup with favorable outcome in adult T-cell acute lymphoblastic leukemia (T-ALL): a Group for Research on Adult Acute Lymphoblastic Leukemia (GRAALL) study. Blood 2009, 113:3918-3924.

14. Palomero T, Lim WK, Odom DT, Sulis ML, Real PJ, Margolin A, Barnes KC, O'Neil J, Neuberg D, Weng AP, Aster JC, Sigaux F, Soulier J, Look AT, Young RA, Califano A, Ferrando AA: NOTCH1 directly regulates C-MYC and activates a feed-forward-loop transcriptional network promoting leukemic cell growth. Proc Natl Acad Sci USA 2006, 103:18261-18266.

15. Weng AP, Millholland JM, Yashiro-Ohtani Y, Arcangeli ML, Lau A, Wai C, Del BC, Rodriguez CG, Sai H, Tobias J, Li Y, Wolfe MS, Shachaf C, Felsher D, Blacklow SC, Pear WS, Aster JC: c-Myc is an important direct target of Notch1 in T-cell acute lymphoblastic leukemia/lymphoma. Genes Dev 2006, 20:2096-2109

16. Chan SM, Weng AP, Tibshirani R, Aster JC, Utz PJ: Notch signals positively regulate activity of the mTOR pathway in T-cell acute lymphoblastic leukemia. Blood 2007, 110:278-286.

17. Palomero T, Sulis ML, Cortina M, Real PJ, Barnes K, Ciofani M, Caparros E, Buteau J, Brown K, Perkins SL, Bhagat G, Agarwal AM, Basso G, Castillo M, Nagase S, Cordon-Cardo C, Parsons R, Zuniga-Pflucker JC, Dominguez M, Ferrando AA: Mutational loss of PTEN induces resistance to NOTCH1 inhibition in T-cell leukemia. Nat Med 2007, 13:1203-1210.

18. Vilimas T, Mascarenhas J, Palomero T, Mandal M, Buonamici S, Meng F, Thompson B, Spaulding C, Macaroun S, Alegre ML, Kee BL, Ferrando A, Miele L, Aifantis I: Targeting the NF-KB signaling pathway in Notch1induced T-cell leukemia. Nat Med 2007, 13:70-77.

19. Buonamici S, Trimarchi T, Ruocco MG, Reavie L, Cathelin S, Mar BG, Klinakis A, Lukyanov Y, Tseng JC, Sen F, Gehrie E, Li M, Newcomb E, Zavadil J, Meruelo D, Lipp M, Ibrahim S, Efstratiadis A, Zagzag D, Bromberg JS, Dustin ML, Aifantis I: CCR7 signalling as an essential regulator of CNS infiltration in T-cell leukaemia. Nature 2009, 459:1000-1004.

20. Radtke F, Wilson A, Mancini SJ, MacDonald HR: Notch regulation of lymphocyte development and function. Nat Immunol 2004, 5:247-253

21. Maillard I, Fang T, Pear WS: Regulation of lymphoid development differentiation, and function by the Notch pathway. Annu Rev Immunol 2005, 23:945-974.

22. Staal FJ, Weerkamp F, Langerak AW, Hendriks RW, Clevers HC: Transcriptional control of T lymphocyte differentiation. Stem Cells 2001, 19:165-179.

23. Carrasco YR, Navarro MN, de Yebenes V, Ramiro AR, Toribio ML: Regulation of surface expression of the human pre-T cell receptor complex. Semin Immunol 2002, 14:325-334.

24. Ciofani M, Schmitt TM, Ciofani A, Michie AM, Cuburu N, Aublin A, Maryanski JL, Zúñiga-Pflücker JC: Obligatory role for cooperative signaling by pre-TCR and Notch during thymocyte differentiation. J Immunol 2004, 172:5230-5239.

25. Rothenberg EV: Negotiation of the T lineage fate decision by transcription-factor interplay and microenvironmental signals. Immunity 2007, 26:690-702.

26. Maillard I, Tu L, Sambandam A, Yashiro-Ohtani Y, Millholland J, Keeshan K, Shestova O, Xu L, Bhandoola A, Pear WS: The requirement for Notch signaling at the $\beta$-selection checkpoint in vivo is absolute and independent of the pre-T cell receptor. J Exp Med 2006, 203:2239-2245.

27. Ciofani M, Zúñiga-Pflücker JC: Notch promotes survival of pre-T cells at the $\beta$-selection checkpoint by regulating cellular metabolism. Nat Immunol 2005, 6:881-888.

28. Li F, Wang Y, Zeller Kl, Potter JJ, Wonsey DR, O'Donnell KA, Kim JW, Yustein JT, Lee LA, Dang CV: Myc stimulates nuclearly encoded mitochondrial genes and mitochondrial biogenesis. Mol Cell Biol 2005, 25:6225-6234.

29. Douglas NC, Jacobs H, Bothwell AL, Hayday AC: Defining the specific physiological requirements for c-Myc in T cell development. Nat Immunol 2001, 2:307-315.

30. Dose M, Khan I, Guo Z, Kovalovsky D, Krueger A, von BH, Khazaie K, Gounari F: c-Myc mediates pre-TCR-induced proliferation but not developmental progression. Blood 2006, 108:2669-2677.

31. Lee MS, Hanspers K, Barker CS, Korn AP, McCune JM: Gene expression profiles during human $\mathrm{CD}^{+}{ }^{+} \mathrm{T}$ cell differentiation. Int Immunol 2004 16:1109-1124
32. Soulier J, Clappier E, Cayuela JM, Regnault A, Garcia-Peydro M, Dombret H, Baruchel A, Toribio ML, Sigaux F: HOXA genes are included in genetic and biologic networks defining human acute T-cell leukemia (T-ALL). Blood 2005, 106:274-286.

33. Ferrando AA, Neuberg DS, Staunton J, Loh ML, Huard C, Raimondi SC, Behm FG, Pui CH, Downing JR, Gilliland DG, Lander ES, Golub TR, Look AT: Gene expression signatures define novel oncogenic pathways in T cell acute lymphoblastic leukemia. Cancer Cell 2002, 1:75-87.

34. Asnafi V, Beldjord K, Libura M, Villarese P, Millien C, Ballerini P, Kuhlein E, Lafage-Pochitaloff M, Delabesse E, Bernard O, Macintyre E: Age-related phenotypic and oncogenic differences in T-acute lymphoblastic leukemias may reflect thymic atrophy. Blood 2004, 104:4173-4180.

35. Bergeron J, Clappier E, Radford I, Buzyn A, Millien C, Soler G, Ballerini P, Thomas X, Soulier J, Dombret H, Macintyre EA, Asnafi V: Prognostic and oncogenic relevance of $T L X 1 / H O X 11$ expression level in T-ALLs. Blood 2007, 110:2324-2330.

36. van Grotel M, Meijerink JP, van Wering ER, Langerak AW, Beverloo HB, Buijs-Gladdines JG, Burger NB, Passier M, van Lieshout EM, Kamps WA Veerman AJ, van Noesel MM, Pieters R: Prognostic significance of molecular-cytogenetic abnormalities in pediatric T-ALL is not explained by immunophenotypic differences. Leukemia 2008, 22:124-131

37. Bray SJ: Notch signalling: a simple pathway becomes complex. Nat Rev Mol Cell Biol 2006, 7:678-689.

38. Barolo S, Stone T, Bang AG, Posakony JW: Default repression and Notch signaling: Hairless acts as an adaptor to recruit the corepressors Groucho and dCtBP to Suppressor of Hairless. Genes Dev 2002, 16:1964-1976

39. Oswald F, Kostezka U, Astrahantseff K, Bourteele S, Dillinger K, Zechner U, Ludwig L, Wilda M, Hameister H, Knochel W, Liptay S, Schmid RM: SHARP is a novel component of the Notch/RBP-JK signalling pathway. EMBO J 2002, 21:5417-5426

40. Borggrefe T, Oswald F: The Notch signaling pathway: transcriptional regulation at Notch target genes. Cell Mol Life Sci 2009, 66:1631-1646.

41. Fraga MF, Berdasco M, Ballestar E, Ropero S, Lopez-Nieva P, Lopez-Serra L, Martin-Subero JI, Calasanz MJ, Lopez dS I, Setien F, Casado S, Fernandez AF, Siebert R, Stifani S, Esteller M: Epigenetic inactivation of the Groucho homologue gene TLE1 in hematologic malignancies. Cancer Res 2008, 68:4116-4122

42. Agrawal S, Archer C, Schaffer DV: Computational models of the Notch network elucidate mechanisms of context-dependent signaling. PLOS Comput Biol 2009, 5:e1000390.

43. Grbavec D, Stifani S: Molecular interaction between TLE1 and the carboxyl-terminal domain of HES-1 containing the WRPW motif. Biochem Biophys Res Commun 1996, 223:701-705.

44. Hasson P, Paroush Z: Crosstalk between the EGFR and other signalling pathways at the level of the global transcriptional corepressor Groucho/TLE. Br J Cancer 2006, 94:771-775.

45. Orian A, Delrow JJ, Rosales Nieves AE, Abed M, Metzger D, Paroush Z, Eisenman RN, Parkhurst SM: A Myc-Groucho complex integrates EGF and Notch signaling to regulate neural development. Proc Natl Acad Sci USA 2007, 104:15771-15776.

46. Buscarlet M, Stifani S: The 'Marx' of Groucho on development and disease. Trends Cell Biol 2007, 17:353-361.

47. Dayyani F, Wang J, Yeh JR, Ahn EY, Tobey E, Zhang DE, Bernstein ID, Peterson RT, Sweetser DA: Loss of TLE1 and TLE4 from the del(9q) commonly deleted region in AML cooperates with AML1-ETO to affect myeloid cell proliferation and survival. Blood 2008, 111:4338-4347.

48. Smith ST, Jaynes JB: A conserved region of engrailed shared among all en-, gsc-, Nk1-, Nk2- and msh-class homeoproteins mediates active transcriptional repression in vivo. Development 1996, 122:3141-3150.

49. Riz I, Lee HJ, Baxter KK, Behnam R, Hawley TS, Hawley RG: Transcriptional activation by TLX1/HOX11 involves Gro/TLE corepressors. Biochem Biophys Res Commun 2009, 380:361-365.

50. Riz I, Hawley TS, Johnston H, Hawley RG: Role of TLX1 in T-cell acute lymphoblastic leukaemia pathogenesis. Br J Haematol 2009, 145:140-143.

51. Teramoto H, Miwa H, Patel V, Letwin N, Castellone MD, Imai N, Shikami M, Imamura A, Gutkind JS, Nitta M, Lee NH: Gene expression changes in a patient presenting nonleukaemic nasal granulocytic sarcoma to acute myelogenous leukaemia using $40 \mathrm{~K}$ cDNA microarray. Clin Lab Haematol 2006, 28:262-266. 
52. Lee JK, Bussey KJ, Gwadry FG, Reinhold W, Riddick G, Pelletier SL, Nishizuka S, Szakacs G, Annereau JP, Shankavaram U, Lababidi S, Smith LH, Gottesman MM, Weinstein JN: Comparing CDNA and oligonucleotide array data: concordance of gene expression across platforms for the $\mathrm{NCl}-60$ cancer cells. Genome Bio/ 2003, 4:R82.

53. Owens BM, Zhu YX, Suen TC, Wang PX, Greenblatt JF, Goss PE, Hawley RG: Specific homeodomain-DNA interactions are required for HOX11mediated transformation. Blood 2003, 101:4966-4974

54. Rice KL, Kees UR, Greene WK: Transcriptional regulation of FHL 1 by TLX1/HOX11 is dosage cell-type and promoter context-dependent. Biochem Biophys Res Commun 2008, 367:707-713.

55. Greene WK, Bahn S, Masson N, Rabbitts TH: The T-cell oncogenic protein HOX 11 activates Aldh1 expression in NIH 3T3 cells but represses its expression in mouse spleen development. Mol Cell Biol 1998, 18:7030-7037.

56. McMurray HR, Sampson ER, Compitello G, Kinsey C, Newman L, Smith B, Chen SR, Klebanov L, Salzman P, Yakovlev A, Land H: Synergistic response to oncogenic mutations defines gene class critical to cancer phenotype. Nature 2008, 453:1112-1116.

57. Gupta-Rossi N, Le BO, Gonen H, Brou C, Logeat F, Six E, Ciechanover A Israel A: Functional interaction between SEL-10, an F-box protein and the nuclear form of activated Notch1 receptor. J Biol Chem 2001, 276:34371-34378

58. Margolin AA, Palomero T, Sumazin P, Califano A, Ferrando AA, Stolovitzky G: ChIP-on-chip significance analysis reveals large-scale binding and regulation by human transcription factor oncogenes. Proc Nat/ Acad Sci USA 2009, 106:244-249.

59. Dohda T, Maljukova A, Liu L, Heyman M, Grander D, Brodin D, Sangfelt O, Lendahl U: Notch signaling induces SKP2 expression and promotes reduction of p27Kip1 in T-cell acute lymphoblastic leukemia cell lines. Exp Cell Res 2007, 313:3141-3152.

60. Riz I, Hawley RG: $\mathrm{G}_{1} / \mathrm{S}$ transcriptional networks modulated by the HOX11/TLX1 oncogene of T-cell acute lymphoblastic leukemia. Oncogene 2005, 24:5561-5575.

61. Zhou X, Benson KF, Ashar HR, Chada K: Mutation responsible for the mouse pygmy phenotype in the developmentally regulated factor HMGI-C. Nature 1995, 376:771-774.

62. Zhou X, Benson KF, Przybysz K, Liu J, Hou Y, Cherath L, Chada K: Genomic structure and expression of the murine Hmgi-cgene. Nucleic Acids Res 1996, 24:4071-4077.

63. Li O, Li J, Droge P: DNA architectural factor and proto-oncogene HMGA2 regulates key developmental genes in pluripotent human embryonic stem cells. FEBS Lett 2007, 581:3533-3537.

64. Wong DJ, Liu H, Ridky TW, Cassarino D, Segal E, Chang HY: Module map of stem cell genes guides creation of epithelial cancer stem cells. Cell Stem Cell 2008, 2:333-344.

65. Gomez-Curet I, Perkins RS, Bennett R, Feidler KL, Dunn SP, Krueger LJ: CMyc inhibition negatively impacts lymphoma growth. J Pediatr Surg 2006, 41:207-211.

66. Huang MJ, Cheng YC, Liu CR, Lin S, Liu HE: A small-molecule c-Myc inhibitor 10058-F4, induces cell-cycle arrest apoptosis, and myeloid differentiation of human acute myeloid leukemia. Exp Hematol 2006, 34:1480-1489.

67. Tworkowski KA, Salghetti SE, Tansey WP: Stable and unstable pools of Myc protein exist in human cells. Oncogene 2002, 21:8515-8520.

68. McMahon SB, Van Buskirk HA, Dugan KA, Copeland TD, Cole MD: The novel ATM-related protein TRRAP is an essential cofactor for the c-Myc and E2F oncoproteins. Cell 1998, 94:363-374.

69. Rogulski K, Li Y, Rothermund K, Pu L, Watkins S, Yi F, Prochownik EV: Onzin, a c-Myc-repressed target promotes survival and transformation by modulating the Akt-Mdm2-p53 pathway. Oncogene 2005, 24:7524-7541.

70. Cox CV, Martin HM, Kearns PR, Virgo P, Evely RS, Blair A: Characterization of a progenitor cell population in childhood T-cell acute lymphoblastic leukemia. Blood 2007, 109:674-682.

71. Borgulya $\mathrm{P}$, Kishi $\mathrm{H}$, Uematsu $\mathrm{Y}$, von Boehmer $\mathrm{H}$ : Exclusion and inclusion of $\alpha$ and $\beta$ T cell receptor alleles. Cell 1992, 69:529-537.

72. Bassing $\mathrm{CH}$, Swat W, Alt FW: The mechanism and regulation of chromosomal V(D)J recombination. Cell 2002, 109(Suppl):S45-S55.

73. Dear TN, Sanchez-Garcia I, Rabbitts TH: The HOX11 gene encodes a DNAbinding nuclear transcription factor belonging to a distinct family of homeobox genes. Proc Nat/ Acad Sci USA 1993, 90:4431-4435.
74. Masson N, Greene WK, Rabbitts TH: Optimal activation of an endogenous gene by $\mathrm{HOX} 11$ requires the $\mathrm{NH}_{2}$-terminal 50 amino acids. Mol Cell Biol 1998, 18:3502-3508

75. Hoffmann K, Dixon DN, Greene WK, Ford J, Taplin R, Kees UR: A microarray model system identifies potential new target genes of the protooncogene HOX11. Genes Chromosomes Cancer 2004, 41:309-320.

76. Riz I, Akimov SS, Eaker SS, Baxter KK, Lee HJ, Mariño-Ramírez L, Landsman D, Hawley TS, Hawley RG: TLX1/HOX11-induced hematopoietic differentiation blockade. Oncogene 2007, 26:4115-4123.

77. Muhr J, Andersson E, Persson M, Jessell TM, Ericson J: Groucho-mediated transcriptional repression establishes progenitor cell pattern and neuronal fate in the ventral neural tube. Cell 2001, 104:861-873.

78. Nagel S, Venturini L, Przybylski GK, Grabarczyk P, Meyer C, Kaufmann M, Battmer K, Schmidt CA, Drexler HG, Scherr M, MacLeod RA: NK-like homeodomain proteins activate NOTCH3-signaling in leukemic T-cells. BMC Cancer 2009, 9:371.

79. Kleinmann E, Geimer Le Lay AS, Sellars M, Kastner P, Chan S: Ikaros represses the transcriptional response to Notch signaling in T-cel development. Mol Cell Biol 2008, 28:7465-7475.

80. Hawley RG, Hawley TS, Cantor AB: TLX1 (HOX11) immortalization of embryonic stem cell-derived and primary murine hematopoietic progenitors. Curr Protoc Stem Cell Bio/ 2008, 7:1F.7.1-1F.7.19.

81. Yu F, Yao H, Zhu P, Zhang X, Pan Q, Gong C, Huang Y, Hu X, Su F, Lieberman J, Song E: let-7 regulates self renewal and tumorigenicity of breast cancer cells. Cell 2007, 131:1109-1123.

82. Fedele M, Fusco A: HMGA and cancer. Biochim Biophys Acta 2010, 1799:48-54

83. Pierantoni GM, Santulli B, Caliendo I, Pentimalli F, Chiappetta G, Zanesi N, Santoro M, Bulrich F, Fusco A: HMGA2 locus rearrangement in a case of acute lymphoblastic leukemia. Int J Oncol 2003, 23:363-367.

84. Odero MD, Grand FH, labal S, Ross F, Roman JP, Vizmanos JL, Andrieux J, Lai JL, Calasanz MJ, Cross NC: Disruption and aberrant expression of HMGA2 as a consequence of diverse chromosomal translocations in myeloid malignancies. Leukemia 2005, 19:245-252.

85. Wang GP, Berry CC, Malani N, Leboulch P, Fischer A, Hacein-Bey-Abina S, Cavazzana-Calvo M, Bushman FD: Dynamics of gene-modified progenitor cells analyzed by tracking retroviral integration sites in a human SCID-X1 gene therapy trial. Blood 2010, 115:4356-4366.

86. Haraguchi N, Inoue H, Tanaka F, Mimori K, Utsunomiya T, Sasaki A, Mori M: Cancer stem cells in human gastrointestinal cancers. Hum Cell 2006, 19:24-29.

87. Sajithlal GB, Rothermund K, Zhang F, Dabbs DJ, Latimer JJ, Grant SG, Prochownik EV: Permanently blocked stem cells derived from breast cancer cell lines. Stem Cells 2010, 28:1008-1018.

88. Staal FJ, de Ridder D, Szczepanski T, Schonewille T, van der Linden EC, van Wering ER, van der Velden V, van Dongen JJ: Genome-wide expression analysis of paired diagnosis-relapse samples in ALL indicates involvement of pathways related to DNA replication, cell cycle and DNA repair, independent of immune phenotype. Leukemia 2010, 24:491-499.

89. Cleaver AL, Beesley AH, Firth MJ, Sturges NC, O'Leary RA, Hunger SP, Baker $D L$, Kees UR: Gene-based outcome prediction in multiple cohorts of pediatric T-cell acute lymphoblastic leukemia: a Children's Oncology Group study. Mol Cancer 2010, 9:105.

90. Moffat J, Grueneberg DA, Yang X, Kim SY, Kloepfer AM, Hinkle G, Piqani B, Eisenhaure TM, Luo B, Grenier JK, Carpenter AE, Foo SY, Stewart SA Stockwell BR, Hacohen N, Hahn WC, Lander ES, Sabatini DM, Root DE: A lentiviral RNAi library for human and mouse genes applied to an arrayed viral high-content screen. Cell 2006, 124:1283-1298.

91. Hawley TS, Telford WG, Ramezani A, Hawley RG: Four-color flow cytometric detection of retrovirally expressed red, yellow, green and cyan fluorescent proteins. BioTechniques 2001, 30:1028-1034.

92. Hawley TS, Telford WG, Hawley RG: "Rainbow" reporters for multispectral marking and lineage analysis of hematopoietic stem cells. Stem Cells 2001, 19:118-124

93. Owens BM, Hawley TS, Spain LM, Kerkel KA, Hawley RG: TLX1/HOX11mediated disruption of primary thymocyte differentiation prior to the CD4+CD8+ double-positive stage. Br J Haematol 2006, 132:216-229.

94. Strack RL, Strongin DE, Bhattacharyya D, Tao W, Berman A, Broxmeyer HE, Keenan RJ, Glick BS: A noncytotoxic DsRed variant for whole-cell labeling. Nat Methods 2008, 5:955-957. 
95. Pui JC, Allman D, Xu L, DeRocco S, Karnell FG, Bakkour S, Lee JY, Kadesch T, Hardy RR, Aster JC, Pear WS: Notch1 expression in early lymphopoiesis influences B versus T lineage determination. Immunity 1999, 11:299-308.

96. Ramezani A, Hawley RG: Generation of HIV-1-based lentiviral vector particles. Curr Protoc Mol Biol 2002, 60:16.22.1-16.22.15.

97. Akimov SS, Ramezani A, Hawley TS, Hawley RG: Bypass of senescence, immortalization and transformation of human hematopoietic progenitor cells. Stem Cells 2005, 23:1423-1433.

98. Krasnoselskaya-Riz I, Spruill A, Chen YW, Schuster D, Teslovich T, Baker C, Kumar A, Stephan DA: Nuclear factor 90 mediates activation of the cellular antiviral expression cascade. AIDS Res Hum Retroviruses 2002, 18:591-604.

99. Teramoto H, Malek RL, Behbahani B, Castellone MD, Lee NH, Gutkind JS: Identification of H-Ras, RhoA, Rac1 and Cdc42 responsive genes. Oncogene 2003, 22:2689-2697.

100. Hu VW, Nguyen A, Kim KS, Steinberg ME, Sarachana T, Scully MA, Soldin SJ, LuU T, Lee NH: Gene expression profiling of lymphoblasts from autistic and nonaffected sib pairs: altered pathways in neuronal development and steroid biosynthesis. PLoS One 2009, 4:e5775.

101. Teramoto H, Castellone MD, Malek RL, Letwin N, Frank B, Gutkind JS, Lee $\mathrm{NH}$ : Autocrine activation of an osteopontin-CD44-Rac pathway enhances invasion and transformation by H-RasV12. Oncogene 2005, 24:489-501.

102. Letwin NE, Kafkafi N, Benjamini Y, Mayo C, Frank BC, Luu T, Lee NH, Elmer $\mathrm{Gl}$ : Combined application of behavior genetics and microarray analysis to identify regional expression themes and gene-behavior associations. J Neurosci 2006, 26:5277-5287.

103. Goutsias J, Lee NH: Computational and experimental approaches for modeling gene regulatory networks. Curr Pharm Des 2007, 13:1415-1436.

104. Tapocik JD, Letwin N, Mayo CL, Frank B, Luu T, Achinike O, House C, Williams R, Elmer Gl, Lee NH: Identification of candidate genes and gene networks specifically associated with analgesic tolerance to morphine. J Neurosci 2009, 29:5295-5307.

doi: 10.1186/1476-4598-9-181

Cite this article as: Riz et al., TLX1 and NOTCH coregulate transcription in T cell acute lymphoblastic leukemia cells Molecular Cancer 2010, 9:181

Submit your next manuscript to BioMed Centra and take full advantage of:

- Convenient online submission

- Thorough peer review

- No space constraints or color figure charges

- Immediate publication on acceptance

- Inclusion in PubMed, CAS, Scopus and Google Scholar

- Research which is freely available for redistribution

Submit your manuscript at www.biomedcentral.com/submit
C Biomed Central 